\title{
DESENHO NA EDUCAÇÃO INFANTIL: a importância e sua contribuição para o desenvolvimento cognitivo e para a alfabetização
}

\author{
DRAWING ON CHILD EDUCATION: the importance and its contribution to cognitive \\ development and literacy
}

\section{Rodrigo Otávio dos SANTOS ${ }^{1}$ Sonia de Fatima RADVANSKEI ${ }^{2}$ Vanessa da Silveira BACHMANN ${ }^{3}$}

\begin{abstract}
RESUMO: Este artigo tem por objetivo discutir o desenho infantil e sua contribuição para o desenvolvimento cognitivo da criança, preparando esse indivíduo para a alfabetização e o letramento significativo. Trata-se de uma pesquisa bibliográfica, de cunho qualitativo. Nesse sentido, será apresentado um breve histórico do desenho e da educação infantil como meio de comunicação, e suas fases segundo autores e a relação com a aprendizagem da criança. Percebeu-se pela pesquisa realizada que há uma necessidade de estimular o desenho da criança, respeitando suas fases pois é uma prática e processo organizativo do desenvolvimento cognitivo infantil e sua relação com o meio o qual faz parte, pois é a primeira etapa básica educacional. $O$ estimulo e o olhar pedagógico é fundamental para o desenvolvimento da linguagem escrita, uma vez que a criança ao desenhar imagina, cria e expressa suas idéias e sentimentos, mostrando sua concepção de mundo, abrindo a possibilidade para o próximo aprendizado, a alfabetização e o letramento. Foram revisitados autores como Lev Vygotsky(1998), Henri Luquet(1969), Viktor Lowenfeld(1977), Rosa lavelberg (2013) e outros mais, essenciais para fundamentar essa pesquisa.
\end{abstract}

Palavras-chaves: Educação. Letramento. Desenho.

ABSTRACT: This article aims to discuss child draws and its contribution to children's cognitive development, preparing this individual for meaningful literacy. This is a qualitative bibliographical research. In this sense, a brief history of children's education and draw as a means of communication will be presented, and their phases according to authors and the relationship with the child's learning. It was perceived by the research carried out that there is a need to stimulate the child's draws, respecting its phases because it is a practice and organizational process of children's cognitive development and its relation with the environment which is part, since it is the first basic educational stage. The stimulus and the pedagogical gaze are fundamental for the development of written language, since the child in drawing imagines, creates and expresses his ideas and feelings, showing his conception of

\footnotetext{
${ }^{1}$ Doutor em História, mestre em tecnologia e graduado em história. Professor titular do programa de pós graduação em educação e novas tecnologias do centro universitário internacional - UNINTER. 2 Doutoranda em Educação da linha Cultura, Escola e Ensino. Professora das séries iniciais e professora de pós graduação. Professora e tutora de Pedagogia do centro universitário internacional UNINTER.

${ }^{3}$ Estudante de Pedagogia no centro universitário internacional - UNINTER. Aluna do Programa Iniciação Cientifica. Estagiária no CEI Tribunal de Justiça.
} 
the world. We have revisited authors such as Lev Vygotsky (1998), Henri Luquet (1969), Viktor Lowenfeld (1977), Rosa lavelberg (2013) and others, essential to support this research.

Key-words: Education. Literacy. Draw.

\section{INTRODUÇÃO}

Essa pesquisa tem como objetivo discutir a importância do desenho da criança na educação infantil e apresentar a contribuição para o desenvolvimento cognitivo e para o trabalho significativo durante o processo de alfabetização. Nesse sentido, investigar-se-á, então, de que forma a produção de desenhos na educação infantil pode contribuir para o desenvolvimento da criança, por meio de estímulos, porém sempre observando e respeitando suas fases.

É na educação infantil, primeira etapa do ensino, que a criança demonstra emoções a partir de seus atos, e uma das principais formas de demonstrar sua percepção de mundo é pelo desenho. Assim, se o profissional reconhecer a importância dessa forma de expressão e como avaliar e promover o seu estímulo, o desenvolvimento da criança poderá ser mais significativo. A criança usa a criatividade ao desenhar, e como já informa Negrine (1994), nessa etapa que o lúdico é essencial, pode revelar a forma como a criança enxerga o mundo. $O$ desenho se torna muito mais do que riscos e rabiscos, contribuindo para vários aspectos como a coordenação motora, cognição e é indispensável para a alfabetização.

Estimular 0 desenho pode ser fundamental por parte dos educadores/docentes. lavelberg (2013) afirma que cabe aos professores promoverem situações e propostas para que os alunos estabeleçam relação entre seus desenhos. Nesse sentido, o desenho também é uma forma de comunicação, devendo ser observado e mediado sempre com cuidado, respeitando a fase que a criança está e focando o desenho como linguagem, como explica Santos (2016).

O desenho é um estágio preparatório para a o desenvolvimento da linguagem escrita, não se satisfazendo com o desenho, a criança abre a possibilidade para o próximo aprendizado. Quando a criança for alfabetizada, não será apenas leitura ou 
escrita, e sim a partir disso estará expressando as suas ideias, assim como acontece no desenho.

Nesse sentido, esses estágios preparatórios do desenvolvimento, explicitados por Vygotsky (1989), são essenciais, e a criança deve ter a todo o momento a possibilidade de realizar experiências com tantos materiais diferentes quanto possível.

A teoria de Lowenfeld (1977) também defende que a criança deve ter acesso a materiais diversos, de consistência e contextura diferentes, que enriquecem a sensibilidade tátil infantil, e isso pode ser facilmente demonstrado pelo uso de diferentes aparatos para o desenho, como tintas, giz, canetas esferográficas entre outros. Outra observação interessante é de como a criança imagina ao desenhar, afirmando que,

à medida que a criança já não se satisfaz com simples relação entre seu pensamento imagístico e o que desenha ou pinta quer agora estabelecer uma relação "verdadeira". "Veja, meu pai tem uma cabeça e duas grandes pernas", portanto meu desenho é "meu pai". Pela primeira vez consegue fixar uma analogia "real". (LOWENFELD, 1977, p.107)

Assim, é importante trazer reflexões sobre como deve ser tratado o desenho infantil, evitando o comum erro de alguns professores que muitas vezes não buscam entender o que a criança quis expressar, infelizmente utilizando um juízo de valor estereotipado que transfere à criança apenas conceitos como "bom" ou "ruim", "feio" ou "bonito".

Esse estudo tem como base a pesquisa bibliográfica, de cunho qualitativo, que segundo Minayo (2001), trabalha com o universo de significados, motivos, aspirações, crenças, valores e atitudes, o que corresponde a um espaço mais profundo das relações, dos processos e dos fenômenos que não podem ser reduzidos à operacionalização de variáveis. Em nosso caso, utilizamos autores para refletir e entender melhor essa primeira etapa da educação na relação com a aprendizagem significativa.

\subsection{Metodologia}

Esta pesquisa apresentada é de cunho qualitativo, ou seja, "explora uma metodologia predominantemente descritiva, deixando em segundo plano modelos matemáticos e estatísticos. Esse tipo de pesquisa, a quantificação dos objetivos 
estudados não é priorizada". (CASARIN, 2012, p.32). Partindo dessa premissa, o texto tem como metodologia uma pesquisa bibliográfica e documental, visando almejar os objetivos propostos por meio de levantamentos de dados bibliográficos.

Foram feitas análises de dados para dar embasamento teórico na perspectiva da pesquisa, onde procurou-se interpretar diretamente os dados coletados. Para Flick (2009, p.134) "todos os tipos de materiais de pesquisa, como anotações, protocolos, notas de campo e diários de pesquisa podem se tornar relevantes para a análise e são produtos dos processos de escrita dos pesquisadores

Desta forma, constatou-se que a pesquisa qualitativa é significativa em nosso trabalho, pois faz o pesquisador ir às fontes e autores para buscar conhecimentos e interpretar as questões pedagógicas da temática proposta em questão.

\section{O DESENHO E SUA CONTRIBUIÇÃO PARA A EDUCAÇÃO INFANTIL E A ALFABETIZAÇÃO}

Inicialmente há a necessidade de conceituar o desenho infantil e suas fases segundo autores que pesquisam essa temática, em seguida as transformações na educação infantil no decorrer dos anos, a importância da qualidade de ensino nessa primeira etapa da educação básica, sua contribuição para o desenvolvimento cognitivo, alfabetização e letramento, finalizando com o olhar pedagógico para a criança e o desenho, com possibilidades de trabalho na educação infantil.

\subsection{A história do desenho e suas fases}

O desenho está diretamente associado à comunicação, como já informa Barbieri (2017), uma vez que está ligada ao homem em grande parte de suas ações. A própria escrita, como sabemos, é um processo onde ideias abstratas ou imagens mentais se convertem em mediações reconhecíveis por meio de convenções arbitrárias de desenhos que representam sons ou ideias, como explica Santaella (1993). Segundo Vygotsky (1998),

Até agora a psicologia tem considerado a escrita simplesmente como uma complicada habilidade motora. Notavelmente, ela tem dado muito pouca atenção à linguagem escrita como tal, isto é, um sistema particular de símbolos e signos cuja dominação prenuncia um ponto crítico em todo o desenvolvimento cultural da criança. (VYGOTSKY, 1998, p.140) 
A comunicação do ser humano ocorre de diferentes formas, conforme o meio em que está inserida. A partir da forma que a criança é criada ela construirá sua identidade e desenvolverá a comunicação, seja oral ou outros modos como gestos, movimentos corporais e também os sinais. Mesmo na pré-história foram desenvolvidas tintas naturais e desenhados símbolos nas pedras, mostrando o desejo inato de comunicação por parte do ser humano.

Já nos primeiros anos de vida a criança aprende a se comunicar através do corpo, da fala, sons e busca descobrir sentido no que acontece ao seu redor, e aos poucos aprende explorar e descobrir novas formas de estar no mundo. Nesse sentido o desenvolvimento se dará conforme o meio que está inserida. Segundo Cartaxo (2013), toda criança aprende se comunicar desde cedo com as pessoas que estão ao seu redor e, cada cultura produz uma forma própria de comunicação.

E como um meio importante de comunicação para a criança, o desenho expressa suas emoções, descobrindo e desenvolvendo suas habilidades. E quando falamos desenho, não se trata de uma representação real de coisas, pessoas ou objetos, mas sim de como a criança enxerga o mundo, revelando seus sentimentos, pensamentos, idéias e principalmente concepção de mundo. Os desenhos sustentam uma tentativa de codificar o mundo em que ela vive, tornando, de certa forma, concretos seus pensamentos abstratos.

A autoria do desenho da criança não se perde quando ela dialoga com outros desenhos, o desenho pode ser mediado pelo educador sem prender a criança a representar o real, desconsiderando o seu modo de desenhar. Para Vygotsky (1998, p.149) ao desenhar a criança utiliza a memória, ela não desenha o que vê e sim o que conhece, ela o faz a maneira da fala, como se contasse uma história. Sendo assim, o desenho é visto como uma linguagem gráfica que surge tendo por base a linguagem verbal. Também salienta que devemos interpretar o desenho da criança como um estágio preliminar da linguagem escrita.

No conceito de Vygotsky (1998), o desenvolvimento do desenho requer duas condições. Sendo uma condição o domínio do ato motor, por isso, para o autor, o desenho é o registro do gesto e logo passa a ser o da imagem. Assim, a criança percebe que pode representar graficamente um objeto. E essa característica é o um indício de que o desenho é precursor da escrita, pois a percepção do objeto, no desenho, corresponde à atribuição de sentido dada pela criança. 
A outra condição fundamental na evolução do desenho é a relação com a fala existente no ato de desenhar. Num primeiro momento, o objeto representado só é reconhecido após a ação gráfica quando a criança fala o que desenhou identificado pela sua semelhança como objeto. Depois ela passa a antecipar o ato gráfico, verbalizando o que vai fazer, indicando que há um planejamento da ação. Por isso, Vygotsky afirma que a linguagem verbal é a base da linguagem gráfica. (1998)

Vygotsky (1998), classificou por etapas as fases do desenho, a primeira chamada etapa simbólica, é descrita como o momento em que as crianças desenham os objetos a partir da memória, sem aparente preocupação com fidelidade à coisa representada, por exemplo, desenha um objeto sem mesmo olhar para ele, é o período em que a criança "representa de forma simbólica objetos distantes de seu aspecto verdadeiro e real" (Vygotsky, 1998, p.149). Segundo esse autor, é grande a arbitrariedade e a licença do desenho infantil nesta etapa.

A segunda etapa, é a simbólico-formalista, quando já se percebe maior elaboração dos traços e formas do grafismo infantil. É o período em que a criança começa a sentir necessidade de não se limitar apenas à enumeração dos aspectos concretos do objeto que representa, buscando estabelecer maior número de relações entre o todo representado e suas partes, indo ao encontro da teoria da Gestalt do objeto, explicitada por Gomes Filho (2009). Percebe-se que os desenhos permanecem ainda simbólicos, mas já se pode identificar o início de uma representação mais próxima da realidade.

$\mathrm{Na}$ terceira etapa, a formalista veraz, as representações gráficas são fiéis ao aspecto observável dos objetos representados, buscando ficar mais próximo da realidade possível, acabando os aspectos mais simbólicos, presentes nas etapas anteriores.

E quarta etapa, sendo a formalista plástica, configura-se como um novo modo de desenhar, pois como um desenvolvimento viso-motor mais acentuado, o sujeito acaba se utilizando de técnicas projetivas e mais realistas. O grafismo deixa de ser uma atividade com fim em si mesma e converte-se em trabalho criador. No entanto, nesta fase infantil há uma separação de interesses e uma diminuição do ritmo dos desenhos que permanecem mais entre aqueles que realmente desenham porque sentem prazer neste ato criador. 
Para Luquet (1969), as fases do desenho infantil também são classificadas em quatro estágios, sendo o primeiro como realismo fortuito, que inicia por volta dos 2 anos de idade, descrito como o momento em que a criança começa a traçar signos sem desejo de representação e descobre por acaso uma analogia com um objeto e passa a nomear seu desenho.

O segundo estágio, chamou de realismo fracassado ou incapacidade sintética, sendo entre 3 e 4 anos, no qual a criança reproduz formas como a figura humana, tendo descoberto a identidade forma-objeto, a criança procura reproduzir esta forma, procurando mostrar o que acha importante.

O terceiro, realismo intelectual, estendendo-se dos 4 aos 10 anos, os desenhos vão sendo mais elaborados, mas ainda apresentando detalhes que fogem da realidade, caracteriza-se pelo fato que a criança desenha não aquilo que vê, mas desenha aquilo que sabe. Nesta fase ela mistura diversos pontos de vista.

No quarto e último, realismo visual, ocorre por volta dos 12 anos, marcado pela descoberta da perspectiva e estratégias, no qual representa com maior fidelidade e mais próximo do real, abandonando as estratégias utilizadas nas etapas anteriores, desenhando apenas os elementos visíveis.

Luquet (1969) classifica o desenho nessas quatro etapas, porém destaca que os estágios não são rígidos, pois cada fase pode se prolongar quando a seguinte já estiver começado, a passagem de um nível para outro há a renúncia de alguns elementos e uma reconstrução dos conhecimentos adquiridos que depende muito das interações da criança em seu meio.

No próximo item será apresentada a discussão entre a importância da educação infantil e a contribuição do desenho para a alfabetização e o letramento.

\subsection{A valorização da educação infantil e a contribuição do desenho para a alfabetização e letramento}

A educação infantil, que já passou por muitas mudanças, e pode ter diferentes significados em diferentes períodos, e atualmente se refere à crianças de 0 a 5 anos de idade. Com a Constituição Federal de 1988 é reconhecido o direito da criança de ser atendida em creches e pré-escolas, sendo vinculado ao atendimento educacional. 
Em 1996 com a Lei das Diretrizes e Bases da Educação Nacional (LDBEN) foi afirmado que a educação infantil é a primeira etapa da educação básica, assegurando todos os direitos a educação e estabelecendo formas de organização para 0 atendimento às crianças de até 6 anos de idade. Mais tarde, houve alteração em relação a idade definida como educação infantil, sendo a partir disso considerada até os 5 anos de idade, ficando assim da seguinte forma, Lei oㅜ 12.796 . De 4 de abril de 2013,

Art. 29, A educação infantil, primeira etapa da educação básica, tem como finalidade o desenvolvimento integral da criança de até 5 (cinco) anos, em seus aspectos físico, psicológico, intelectual e social, complementando a ação da família e da comunidade. (Brasil, 2013)

Esta primeira etapa da educação básica busca um caráter intencional de ensino, com uma organização de conteúdos considerando as especificidades do desenvolvimento da criança. Portanto, atualmente, A educação infantil é uma etapa da educação básica Brasileira conforme define o INEP:

\begin{abstract}
A Lei de Diretrizes e Bases da Educação Nacional (LDB - 1996) define que a Educação Infantil deve ser oferecida em creches ou em entidades equivalentes, para crianças de 0 a 3 anos de idade, e em pré-escola, para crianças de 4 a 6 anos. Ainda que não obrigatória, a Educação Infantil é um direito público, cabendo ao município a expansão da oferta, com o apoio das esferas federal e estadual. (INEP, 2011)
\end{abstract}

Tal etapa é de extrema importância na formação do cidadão, assim como afirma Makarenko (apud Silva 2010 p. 24): "A educação desempenha um papel particularmente importante durante os primeiros anos de vida, ao longo dos quais se assiste a um desenvolvimento intensivo das faculdades intelectuais".

Para tanto, deve-se estabelecer um sistema de ensino significativo, no qual a aprendizagem impulsione o desenvolvimento. Os cuidados ministrados nas creches incluem criação de um ambiente que garanta segurança física, que tenha oportunidade de explorar e construir sentidos, que se preocupe com a forma como elas estão se percebendo como sujeito, que seja cuidada e educada, que se sinta acolhida, que seja possível desenvolver sua identidade e autonomia. Esses objetivos serão alcançados através da proposta pedagógica das instituições quando colocada em prática, assim há a interação com o meio e as com atividades propostas.

O desenho como uma das ferramentas mais utilizadas por educadores, do mesmo modo que foi um dos primeiros meios de comunicação na pré-história, 
continua sendo o primeiro traço da criança, nesse sentido, conhecer o desenho infantil e permitir que a criança seja protagonista de seu trabalho, é um ato de respeito. Ao analisar sem interferir na intencionalidade dela, pode se ver seu desenvolvimento motor e cognitivo.

Em cada idade a criança apresentará diferentes maneiras de desenhar, maneiras que não serão iguais para todas. Os professores devem levar em conta suas peculiaridades, o meio social e econômico que está inserida, é, analisando por etapas, é possível perceber quando estará preparada para receber o processo de alfabetização, pois segundo Lowenfeld e Brittain(1977, p. 381)

\begin{abstract}
A criança pré-escolar aprende de modo mais ativo que passivo, isto é, sua interação real com o meio, o tocar, ver e manipular fazem parte do seu progresso total, estando intimamente ligados ao seu desenvolvimento cognitivo e perceptivo. Neste período a criança apresenta escasso conceito de tempo; em grande parte, o mundo, para ela, tem pouco passado ou futuro, melhor dizendo, o mundo é.
\end{abstract}

O conhecimento que um educador tem sobre desenhos infantis pode permitir que veja o progresso da criança, analisando e compreendendo o processo que é percorrido até ser finalizado. Ter contato com demais tipos de desenhos ou obras pode se tornar ponto de partida para outros desenhos, e não se perde a autoria por isso.

Para tanto, a creche e o educador, devem reconhecer o desenho infantil como linguagem e utilizá-lo para o processo de aquisição da língua escrita, enfatizando a afirmação de Vygotsky (1998) que desenhar e brincar deveriam ser estágios preparatórios ao desenvolvimento da linguagem das crianças, sendo seu meio de expressão, é considerada uma linguagem necessária para a aquisição da escrita na alfabetização.

A criança já desde pequena observa o ambiente que está inserida, e mesmo antes de aprender escrever, tem contato com as letras e palavras no seu cotidiano, nos textos da televisão, computador, propagandas e tudo mais que está em sua volta. E entretanto, é a alfabetização a fase de extrema importância, onde a criança estará ainda mais inserida na sociedade, uma vez que com a aquisição da leitura e escrita há uma nova visão do mundo em que vive, tendo a possibilidade de se comunicar através da escrita e expressar o que sente, assim como fazia no desenho. 
Para Pillar (1996), a criança chega ao nível alfabético, abandonando a análise silábica na construção de palavras e estabelece uma correspondência entre grafemas e fonemas, atingindo finalmente o sistema de escrita através do seu reconhecimento, portanto, se faz necessário a valorização do desenho infantil como primeira escrita, sendo um alicerce para chegar à alfabetização, e apesar de serem linguagens diferentes, elas se complementam.

\title{
2.3 O desenho infantil e o olhar pedagógico
}

A educação infantil, por muito tempo não recebeu a atenção necessária, sendo a principal função desempenhada pelos profissionais 0 ato de cuidar das necessidades básicas da criança, como se fossem babás, não sendo exigido ensino superior ou formação especifica para exercer tal função, desta forma não recebendo o olhar pedagógico nessa fase da criança.

Aos poucos essa etapa foi ganhando espaço na educação, e, como já vimos, em 1996 com a Lei 9.394, ficou estabelecida a educação infantil como primeira etapa da educação básica, e formação mínima exigida para tal função, sendo esse um grande avanço para um melhor atendimento dessa etapa, conforme artigo 62,

\begin{abstract}
A formação de docentes para atuar na educação básica far-se-á em nível superior, em curso de licenciatura, de graduação plena, em universidades e institutos superiores de educação, admitida, como formação mínima para o exercício do magistério na educação infantil e nas quatro primeiras séries do ensino fundamental, a oferecida em nível médio na modalidade Normal. (BRASIL, LDBEN P.20)
\end{abstract}

Além do ensino superior, também ficou estabelecido a oferta de formação continuada para os profissionais da área. E, com a lei garantido o direito da criança na educação infantil, logo foi preciso um direcionamento pedagógico. Buscando qualidade para esse ensino em 1998 foi apresentado o Referencial Curricular Nacional para Educação infantil (RCNEI), como primeira proposta voltada para o ensino da primeira etapa básica. Apresentando objetivos gerais e específicos, conteúdos e ações didáticas organizadas para diferentes faixa etárias desta etapa.

Este referencial, como o próprio nome indica, é um documento que não é de caráter obrigatório, mas traz reflexões relevantes para a organização do professor, em relação a formação do sujeito e desenvolvimento das capacidades afetivas, tratando também as diferentes linguagens construídas pela criança. Cada instituição 
que oferta educação infantil tem autonomia para elaborar e desenvolver seu projeto pedagógico, devendo se comprometer com os padrões de qualidade. Garantindo o bem-estar das crianças no processo de aprendizagem, conforme RCNEI (1998)

\begin{abstract}
No processo de construção dessa aprendizagem as crianças cometem "erros". Os erros, nessa perspectiva, não são vistos como faltas ou equívocos, eles são esperados, pois se referem a um momento evolutivo no processo de aprendizagem das crianças. Eles têm um importante papel no processo de ensino, porque informam o adulto sobre o modo próprio de as crianças pensarem naquele momento. $\mathrm{E}$ escrever, mesmo com esses "erros", permite às crianças avançarem, uma vez que só escrevendo é possível enfrentar certas contradições. (BRASIL, RCNEI p. 128)
\end{abstract}

Nesse sentido, respeitar a fase de desenvolvimento da criança, sabendo que haverá de fato "erros", que devem ser esperados por parte do educador, pois a criança está em processo de aprendizagem. Quando desenha, sendo um ato particular da criança, com sua imaginação ela cria, inventa, muitas vezes não fazendo da forma ou cor que seria considerada correta para nossos olhos, mas um professor, ao tomar a decisão de intervir, perde a essência e autoria da criança.

A partir de tais reflexões, observa-se a necessidade de que essas instituições promovam ações que o aluno possa estabelecer uma relação com o desenho por ele mesmo. Observar com olhar pedagógico é o papel do educador, deixando a criança livre para mostrar o que ela deseja, se existir tais de equívocos de intervenção, a criança pode se oprimir e perder a ludicidade que é indispensável nessa fase, uma vez que, segundo lavelberg (2013, p.30),

\begin{abstract}
Observam-se equívocos didáticos nas situações em que se pede às crianças para agir fora do universo infantil e dos artistas, pois separa-se o desenho da criança da sua autoria e do seu potencial criativo. São exemplos dessas demandas os desenhos para colorir feitos a partir de formas estereotipadas sem qualidade. Por exemplo: uma festa junina pode ser mote para propostas de desenho autoral; mas pedir as crianças para preencherem com cor desenhos de bandeirinhas e fogueiras sem qualidade artística não corresponde à natureza criativa do desenho infantil.
\end{abstract}

Desenhos oferecidos à criança que sejam impressos também poderem diminuir a criatividade por parte dela. O desenho não é uma atividade de apenas passar o tempo, mas sim uma grande ferramenta pedagógica que permite perceber o que a criança esta dizendo através do desenho, e que possibilita a aproximação entre professor e aluno.

O desenho é um convite para que o adulto entre no mundo da imaginação da criança, uma vez que segundo Santos Neto e Silva (2013 p.47), nas crianças a 
criatividade é atrelada a um aspecto de vital importância, a imaginação. E sem ela, os pequenos não se desenvolvem de maneira plena. Desta forma ressalta sobre a recepção dos adultos para o desenho da criança, pois ali está o seu trabalho, realizado com sua imaginação, e não da maneira que seja correta aos nossos olhos.

O desenho é uma importante ferramenta pedagógica para essa etapa da educação, de forma que não é uma atividade para ocupar o tempo em sala, mas sim deve ser planejada, propondo os mais variados materiais e espaços significativos. Para que essas produções de desenho fiquem ainda mais interessantes, os educadores devem mostrar interesse, desta forma valorizando os desenhos de autoria da criança, sendo receptivos com o desenho, sabendo que nem todas as crianças se desenvolvem no mesmo tempo.

Podem ser organizadas propostas em forma de projetos, histórias, pinturas, visitas a parques e museus, e com os mais diferentes temas, é possível preparar diversos materiais para a educação infantil, adaptando a cultura local aos recursos disponíveis. lavelberg (2013) apresenta possibilidades de trabalho com desenho, através de fotografias, carimbos, imagens, recortes, colagens e várias outras formas possíveis. É um universo infinito a ser explorado pelos professores.

E com todas essas variadas opções de trabalho em sala, muitos professores usam desenhos impressos, para que as crianças apenas pintem e ainda com as cores "adequadas" para nossa realidade, não abrindo as portas para a criatividade, imaginação, e demais quesitos que são fundamentais. Mas com tantas formas de trabalhar, o que poderia acarretar na escolha por esse método? Vianna (2010, p.193) afirma que o docente utiliza este método

\footnotetext{
Pela falta de recursos, de alternativas, de informação, por comodismo, de coragem de se contrapor, mas, principalmente pela necessidade de pertencer a um grupo, pela necessidade de se "sentir junto", de estar em coesão com ele, praticando o que manda o senso comum e, assim ser considerado adequado, conveniente, amável e competente.
}

Diante da afirmação da autora, pode se refletir que essa escolha de trabalhar o desenho já se tornou um método tradicional, então o professor pode ter vontade de fazer a diferença, trazendo a inovação para seus alunos, mas acaba não fazendo, para agradar colegas e direção escolar, para continuar parte do grupo padrão, mesmo que vá contra suas idéias de trazer o novo para sala de aula. 
Contudo, vive-se um momento da história que o novo pode ser questionado, mas também estimulado, e é muito possível trazer melhoramentos para a sala de aula. Os professores, como vimos, têm ao seu favor muitos autores defendendo essa outra forma de trabalho com o desenho infantil.

\section{CONSIDERAÇÕES FINAIS}

Neste artigo foi apresentado o desenho na educação infantil, porém se trata de um tema amplo e praticamente inesgotável, assim, foi enfocada a sua importância para o desenvolvimento da criança pequena. Para tanto, houve a necessidade da retomada de uma breve trajetória da educação infantil, a história do desenho, pontuando algumas de suas fases segundo autores, e sua contribuição para a alfabetização e letramento, finalizando sobre possibilidade de trabalho dos professores na utilização do desenho.

A educação infantil, primeira etapa da educação básica busca um caráter intencional de ensino, a organização de conteúdos considerando as especificidades do desenvolvimento da criança, estabelecendo um sistema de ensino significativo, no qual a criança seja educada, que se sinta acolhida, que seja possível desenvolver sua identidade e autonomia através do trabalho em sala de aula.

O desenho é uma ferramenta a ser utilizada em sala, e deve ter um olhar diferenciado por parte do educador, analisando e compreendendo o processo que é percorrido até ser finalizado. A prática de desenhar é indispensável para a criança, sendo a infância uma época de descobertas. Cabendo ao educador o estimulo, e reconhecimento do desenho infantil como linguagem e utilizá-lo para o processo de aquisição da língua escrita.

Ao desenhar, a criança expressa suas emoções, revelando seus sentimentos, pensamentos, idéias, não se tratando de uma representação real das coisas, mas sim de como a criança enxerga o mundo. Não podendo perder a essência do desenho, quando é mediada por um educador.

Não se satisfazendo com o desenho, a criança abre a possibilidade para o próximo aprendizado, iniciando a alfabetização. E a partir dela a criança estará ainda mais inserida na sociedade. Com a aquisição da leitura e escrita, a criança tem uma nova visão do mundo em que vive, tendo a possibilidade de se comunicar através da 
escrita e expressar o que sente, assim como fazia no desenho. Portanto, se faz necessária a valorização do desenho infantil como primeira escrita, sendo um alicerce para chegar à alfabetização, pois, apesar de serem linguagens diferentes, se complementam.

Sendo uma importante ferramenta pedagógica para essa etapa da educação, o desenho é um convite para que o adulto entre no mundo da imaginação da criança, de forma que não é uma atividade para ocupar o tempo em sala, mas sim deve ser planejada, podem ser ofertadas propostas com os mais diferentes temas, é possível preparar diversos materiais para a educação infantil, entretanto, fatores como comodismo, falta de recursos, informação, necessidade de permanecer a um grupo, entre outros, são os motivos que os professores permanecem utilizando essa forma tradicional de trabalhar o desenho.

Trabalhar o desenho de uma forma que provoque, incentive e desenvolva o aluno é uma escolha do professor, se irá ou não inovar sua forma de ensino. Buscar recursos, novas idéias, é algo a cada dia mais possível, a tecnologia é grande aliada do professor, além dos cursos de extensão e pós-graduação que tratam desse tema.

Percebe-se que esse tema é de extrema relevância, e sugere-se que para que se tenham dados reais uma pesquisa de prática experimental como uma pesquisa-ação com professores e alunos seria de fundamental importância para uma organização de amostras e análise criteriosa para fundamentar ainda mais a pesquisa.

\section{REFERÊNCIAS}

BARBIERI, Daniele. As linguagens dos quadrinhos. São Paulo: Peirópolis, 2017. CARTAXO, S.R.M. Pressupostos da educação infantil. Curitiba: InterSaberes, 2013.

CASARIN, Helen de Castro Silva; SAMUEL José Casarin. Pesquisa científica: da teoria à prática. Curitiba, InterSaberes, 2012.

FERREIRA, Larissa David. A importância do desenho na alfabetização de crianças.

Disponível em:

http://www.unisalesiano.edu.br/simposio2015/publicado/artigo0100.pdf Acesso em: $23 / 04 / 2017$ 
FLICK, Uwe. Desenho da pesquisa qualitativa. Tradução Roberto Cataldo Costa. Porto Alegre: Artmed, 2009.

GOMES FILHO, João. Gestalt do Objeto. Curitiba: Escrituras, 2009

IAVELBERG, Rosa. Desenho na educação infantil. São Paulo: Melhoramentos, 2013.

LOWENFELD, Viktor. A Criança e sua Arte. 2 ed. São Paulo: Mestre Jou, 1977.

LUQUET, G. H. O desenho infantil. Porto: Civilização editora, 1969.

MEC. Referencial curricular nacional para a educação infantil/Ministério da Educação e do Desporto, Secretaria de Educação Fundamental. - Brasília, 1998. Volume 3: Conhecimento de mundo. Disponível em:http://portal.mec.gov.br/seb/arquivos/pdf/volume3.pdfAcesso em: 20/05/2017 MINAYO, M. C. S. O desafio do conhecimento. São Paulo: HUCITEC, 2007 NEGRINE, Airton. Aprendizagem e desenvolvimento infantil. Porto Alegre: Propil, 1994.

NETO, Elydio Santos. Histórias em quadrinhos e práticas educativas. São Paulo: Criativo, 2013.

OLIVEIRA, Z. M. R. Educação infantil: Fundamentos e Métodos. São Paulo: Cortez, 2010.

PILLAR, Analice Dutra. Desenho e escrita como sistema de representação. Porto Alegre: Artes Médicas, 1996.

SANTAELLA, Lucia. Palavras, imagens \& enigmas. In: Revista USP № 16 São Paulo: 1993.

SANTOS, Rodrigo Otávio dos. Fundamentos da Pesquisa Histórica. Curitiba: Intersaberes, 2016.

SEVERINO, Antônio Joaquim. Metodologia do trabalho científico. 23. ed. rev e atualizada - São Paulo: Cortez, 2008.

SILVA, Maria Elisandre da. A importancia da educação infantil para odesenvolvimento e a aprendizagem da criança, Londrina, 2010

VIANNA, Maria Leticia Rauen. Desenhando com todos os lados do cérebro. Curitiba: Ibpex, 2010.

VYGOTSKY, L.S. A formação social da mente. São Paulo: Martins, 1998. 